\title{
Regulations on Three Big Data Discriminations Inducing Transaction Costs----From the Perspective of Legal Aid
}

\author{
Xiu Ye ${ }^{1, *}$, Huihui Dong ${ }^{2}$
}

\author{
${ }^{1}$ Guangzhou Xinhua University \\ ${ }^{2}$ Guangzhou Xinhua University \\ *Email:574000242@qq.com.
}

\begin{abstract}
Individuals in transactions suffer from three types of big data discrimination: biased selection, false association, and malicious recommendation, which could induce additional transaction cost. Through algorithm model, enterprises process and derive the initial data of individuals. In this process, enterprises have added unfavorable algorithmic judgment conditions for individuals, restricting the individual's freedom of transaction and the right to choose, leading to unfairness in the transaction and increasing transaction cost for individuals. This article proposes that in order to suppress the adverse consequences of big data discrimination, data and algorithms should be included in regulatory objects at the same time, early warning mechanisms should be established, and supervising agencies should be stationed in data platforms by means of legal aid.
\end{abstract}

Keywords: Big Data Discrimination, Transaction Cost, Legal Aid.

\section{INTRODUCTION}

On 22 October 2020, the spokesperson of the Ministry of Industry and Information Technology pointed out at a press conference: in order to strictly implement the "Network Security Law", through the promulgations of the "Telecom and Internet Users personal Information protection Regulations" on APP four aspects of 10 categories of special rectification, increase the protection of personal information, covering 400,000 Apps. The Civil Code of the People's Republic of China, passed in May 2020, has already made it clear that personal information is a citizen's right and is protected by law. In the context of the rise of ecommerce, personal information is mostly used in the scope of economic, social and other civil laws, personal information through the form of data and the use of algorithms to provide convenience for enterprises and individuals, but also the emergence of using big data algorithms to discriminate against individuals.

\section{THREE TYPES OF BIG DATA DISCRIMINATION}

Aziz. Z(2019) argues that the creators of algorithms often create false associations between data and the behavior of specific groups, with discriminatory consequences for those groups[1]. Big data discrimination can be divided into three main types: biased selection, false association, malicious recommendation, etc. Relying only on administrative and judicial departments to combat big data discrimination is obviously insufficient. It is necessary to introduce social organizations to provide civil legal assistance to the discriminated objects, so as to improve the governance efficiency of suppressing big data discrimination.

\subsection{Biased Selective Big Data Discrimination}

Biased selective big data discrimination violates the justice of information distribution. Based on their own biases, data users set classification standards that do not conform to legal and moral constraints on the collected individual data, resulting in the actual disadvantage of individuals under the operation of such standards. For example, in the delivery platform, there are problems such as unreasonable time planning and route planning when sending orders to riders, resulting in riders taking the wrong route when delivering orders, and fines due to lack of time. Pauline T. Kim (2017) pointed out that based selective big data discrimination strengthens people's stereotypes in the past, making the disadvantaged individuals even more disadvantaged, 
forming a vicious circle[2]. In biased selective big data discrimination, individual information data itself is objective and neutral, and is obtained based on legal means, but in the process of data analysis and mining, illegal standards are set, resulting in discriminatory consequences. For example, the recruitment platform, acting as an agent for an enterprise, provides applicants with information in their resume and sets discriminatory screening criteria such as gender, educational background and work experience, which results in a disadvantageous position for the applicants.

In Chapter 4 of the Network Security Law, relevant provisions are stipulated on network information security, but biased selective big data discrimination does not violate the legal provisions of information collection and information storage, nor does it violate the specific provisions of information release and transmission in Article 47 and 48.Biased selective big data discrimination has a certain concealment in practice, and only shows adverse consequences. Data users are required to rectify the violations against the principles of honesty, credit, public order and good customs. In the multiple batches of reasons for rectification and removal of apps published by the Ministry of Industry and Information Technology from 2020 to 2021, there are reasons such as illegal collection of information and excessive request for information, but there is no definition in the selection of system data processing standards.

\subsection{False Correlation Big Data Discrimination}

False correlation big data discrimination violates information procedural justice. Data users can use algorithms to associate multiple data of the data subject through the preparation of data processing programs and deduce the characteristics of the data subject on this basis to classify the data subject. Solon.Barocas \& Andrew.D.Selbst (2016) supposed that this kind of discrimination through attribute association seems objective and neutral in appearance, so it has a strong concealment and is difficult to be recognized by people[3].

False correlation big data discrimination refers to the compulsory and unnecessary association of some data through the program, resulting in the creation of false relationships among multiple information of the data subject, which leads to the disadvantageous position of the data subject in the data retrieval operation and service provision in the later period of the system. For example, some car-buying platforms survey major car brands appearing in entertainment places, and attribute some drivers of frequently appearing brands to groups who are greedy for enjoyment and excessive entertainment, which forms a bad judgment guide for the car brand and buyers. In the process of job hunting, college ranking is related to the intelligence and ability of college graduates, leading to social discrimination against college graduates, second and third degree graduates. False correlation big data makes false correlation hypothesis based on the information collected by legal compliance, deduces the non-existent characteristics of the subject, and forms the actual discrimination judgment and behavior.

Article 43 of the Network Security Law stipulates that individuals have the right to ask network operators to delete their personal information. If any error is found in the personal information collected or stored by the network operator, it shall have the right to request the network operator to correct it. However, the personal information collected and stored by false correlation big data often does not have errors. Instead, there are improper behaviors in the process of reprocessing the information program through the program, which leads to the emergence of personal adverse consequences. Therefore, the discrimination of false correlation big data is also hidden, which requires professionals and professional means to find out. Individuals often lack knowledge and relevant technology, and suffer adverse consequences.

\subsection{Maliciously recommended big data discrimination}

Malicious recommendation of big data discrimination in the Network Security Law in Article 48 has a more explicit provisions, that is, "any individual and organization sent electronic information, provided application software, shall not set malicious programs, shall not contain the law, administrative regulations prohibited the release or transmission of information. "In addition, article 10 of the Provisions on the Protection of Telecommunications and Internet Users' Personal Information stipulates that "information shall not be sold or illegally provided to others". Malicious recommendation big data discrimination mainly occurs between different information platforms or subsystems under the platform. After personal data is shared, products, services and other commodities are recommended against personal will, or even traps are set to push leading information, resulting in individuals in a disadvantageous position. The "abuse of personal data" was included in a 2021 overhaul of apps by the Ministry of Industry and Information Technology. The malicious recommendation of big data discrimination is easier to distinguish and be detected, which is also the focus of the administrative and judicial departments. There are also many restrictions in the provisions of laws and regulations. 


\section{CIVIL LEGAL AID FOR INDIVIDUALS WHO SUFFER FROM BIG DATA DISCRIMINATION}

Richard A. Primus(2003) pointed out that Algorithmic decision-making is not open, questioned or explained, which makes it difficult to check and balance the algorithmic power of "quasi-public power", resulting in the imbalance between power and right, thus forming the "algorithmic tyranny"[4].

\subsection{The development of civil legal aid in China}

Before the 1990s, there was little understanding of legal aid in China, and the lawyer system had not been reformed, so the government became the main body of legal aid. The introduction of the Legal Aid Regulations in 2003 marked that the institutionalization of legal aid was on the right track. The six provisions listed in article 10 , together with the local provisions, constitute the main contents of the scope of China's civil legal aid. On the one hand, the establishment of civil legal aid system reflects the justice and superiority of China's socialist system, on the other hand, it reflects the responsibility of our government to protect the rights of citizens. Due to historical reasons, "Legal Aid Regulations" still has many shortcomings, such as the uncertainty of the provisions, provisions of local, has not formed a unified legislation in the whole country. In order to make up for the shortage, legal aid was incorporated into the legislative plan in October 2018 after being included in the social public service plan of The State Council in 2017. Legal aid includes criminal legal aid and civil legal aid. Criminal legal aid has become a hot topic of discussion, while civil legal aid has a lack of attention.

According to the Regulations on Legal Aid, the targets of civil legal aid are mainly economic difficulties and vulnerable groups. With the change of domestic economic, social and political environment, more and more groups need civil legal aid, but it does not mean that the group has economic difficulties or is in a vulnerable position. For example, individuals discriminated against by big data are suffering from rights violations rather than economic difficulties, so civil legal aid should cover the whole group of citizens. Secondly, after years of reform of the lawyer system, China has a large number of professional lawyers and legal service agencies, which can bear the task needs of civil legal aid. Thirdly, the Civil Code plans the rights of the subject in the civil field, and the legislative work of legal aid is gradually deepened, which makes the legal basis of civil legal aid more solid. Finally, the reform of government institutions in China under the concept of rule of law requires the participation of multiple subjects in social livelihood services, and changing the single government main service mode can further promote the fairness and efficiency of China's social governance.
Therefore, under the background of legislative planning, expanded coverage, diversified social governance subjects and increasing professional organizations, China's civil legal aid system is bound to enter a stage of rapid development.

\subsection{The Main Legislative Points of Civil Legal Aid}

The Legal Aid Regulations stipulate that civil legal aid covers low-income and vulnerable groups, which obviously does not meet the requirements of the current comprehensive social development. The Civil Code gives citizens the right to information, so the legislation should make it clear that individuals or organizations who suffer from big data discrimination should be the objects of legal protection. Second, big data information is widely used in business, society, culture and other aspects in China. In order to adapt to the requirements of globalization, the regulations on Legal Aid that exclude foreigners, stateless persons, legal persons and unincorporated organizations should be revised. As a unified national law, the civil legal aid subject to big data discrimination shall cover all citizens, legal persons and non-legal persons, as well as foreigners, stateless persons and overseas organizations under the jurisdiction of Chinese laws.

The subject, object and legal relationship in the law are the three basic elements, and the rights of the subject of civil legal aid for individuals who suffer from big data discrimination must be clearly defined. The rights of the subject can be stipulated by combing the civil Code, the Network Security Law, the economic law and the civil law in many laws. Right to the use of the first subject of the ownership of the information, clear, although the invisibility of information leads to define there are some difficulties, but information attached subject exist, ownership should be relegated to the main body, to use and can be used to distinguish by using the object and body part using information belongs to the main body, government regulators, using a finite bound to regulators and the main body, The information used by a third party belongs to the subject; Secondly, the rights of subject data collection, storage and reuse should be subject to voluntary recognition conditions, so that other institutions can use them within the scope of the regulations. Thirdly, the right to know about the use of the subject data must be defined in the law. The right to know includes the use of the data, the platform and organization of the data, the structured interpretation of the data used by the algorithm, etc. Finally, the restriction and revocation rights of the subject to the use of data must be stipulated.

The data in the scope of civil legal aid must be clear. First, the content of the data must not contravene the scope of existing law. Secondly, the form of data collection and storage must be clear; Thirdly, the 
processing procedures used by the data must be explained, and the purpose, use and consequence assessment of the algorithmic procedures generated by the data processing and use must be specified. Finally, the data includes not only the initial information, but also the content of the generated data after the data is processed by the algorithm program.

Many cases such as big data discrimination show the complexity and professionalism of the process, so the implementation and enforcement of laws can only improve the efficiency of social governance with the participation of social organizations. On the one hand, after more than 30 years, the number of law firms and lawyers in China has been greatly increased, which can provide legal services for individuals who suffer from big data discrimination. On the other hand, big data requires technical support from information professionals to ensure better evidence support for the implementation of legal provisions. However, the legal status of social organizations must be clearly defined in big data legal aid legislation. First of all, social organizations assume the function of professional service support, so the legal effect of their responsibilities and actions must be defined. Secondly, in the process of providing services, the responsibilities and roles of social organizations must be defined in law;Thirdly, the responsibilities and obligations of social organizations in the process of participation must be standardized; Finally, the platform for information sharing between social organizations and government regulatory agencies in the process of governance must be defined.

\section{CONCLUSIONS AND FUTURE WORK}

Biased selection, false association and malicious recommendation are three kinds of big data discrimination, which are implemented by the data platform in a dynamic process and change with the development of business environment, market demand and information technology. Mark MacCarthy (2018) pointed that it is difficult for regulators to predict dynamic discrimination in advance by relying only on expost behavior evaluation or using spot check measures to reduce losses[5]. Therefore, if the legal aid legislation provides the right of the regulatory agencies to supervise the permanent residence of the data platform, and designs the permanent supervision mechanism in the practice process, then the discriminatory behavior of big data will be stopped before and during the event, and the social operation cost brought about afterwards will be reduced.

Biased selection and false correlation of big data discrimination are relatively hidden, which are rooted in data collection and storage specifications, and the data is true. However, after the data is set by algorithm standards and algorithm programs, the derivative information generated will cause adverse consequences to individuals. Therefore, in the process of discrimination against big data, civil aid laws should not only focus on the objectivity and access channels of data, but also include the supervision of data algorithms. In practice, not only legal professional institutions but also information technology service institutions are required to intervene in order to achieve effective supervision under the dual control of law and information technology[6].

\section{AUTHORS' CONTRIBUTIONS}

Big data discrimination is widespread and diverse in society. The author classifies the types of big data discrimination and summarizes them into three types of big data discrimination. Through the abstraction after classification, the inherent characteristics of the three kinds of big data discrimination are analyzed, and the bad legal and social consequences of the three kinds of big data discrimination are pointed out. Combining with China's current civil law system, it proposes legal suggestions to curb big data discrimination from four aspects: the subject and object of the law, the object of legal aid, legal rights, and the aid organization.

\section{ACKNOWLEDGMENTS}

During the writing of the thesis, I consulted a large number of online materials. These materials provide important facts for the writing of this article, and also draw on the writing ideas of some other scholars. This study is partly sponsored by "Research on Ideological and Political Construction of Patriotism Course in International Law" of 2020 Provincial Higher Education Teaching Reform Project under Guangdong Provincial Department of Education. This expresses my heartfelt thanks.

\section{REFERENCES}

[1] Aziz Z.Huq,"Racial Equity in Algorithmic Criminal Justice”,Duke Law Journal, vol.68, 2019, PP.10431068 .

[2] Pauline T. Kim,"Data - Driven Discrimination at Work", William and Mary Law Review,vol.58, 2017, PP.850-867.

[3] Solon Barocas \& Andrew D.Selbst,"Big Data's Disparate Impact",California Constituational Law Review, vol.104, 2016, PP.671-691.

[4] Richard A.Primus, "Equal Protection and Disparate Impact:Round Three”,Harvard Law Review, vol.117,2003,PP.494-504.

[5] Mark MacCarthy,"Standards of Fairness for Disparate Impact Assessment of Big Data 
Algorithms", Cumberland Law Review,vol.48, 2018,PP.67-77.

[6] Melissa Hamilton, "The Biased Algorithm: Evidence of Disparate Impact on Hispanics", American Criminal Law Review,vol.56,2019, PP.1553-1573. 